\title{
Criteria and Indicators for Evaluating the Effectiveness of The Development of Regional Tourism Infrastructure
}

\author{
Dilshod Abduraimov, Samarkand Institute of Economics and Service Republic of Uzbekistan
}

\begin{abstract}
This article examines the criteria and indicators for determining the economic efficiency of regional tourism, the classification of indicators for assessing the effectiveness of tourism infrastructure components, the function of resource efficiency in the industry, internal and external factors affecting the economic efficiency of hotels, scientific and methodological aspects of profit formation.
\end{abstract}

Keywords: Tourism, Tourism Infrastructure, Tourism Industry, Criteria, Indicators, Economic Efficiency, Hotel, Profit, External and Internal Factors.

Received: 14.12 .2020 Accepted: 12.01 .2021

Published: 05.02.2021

\section{INTRODUCTION}

An infrastructure includes a set of economic sectors that serve the main production, as well as infrastructure facilities that belong to the main production sectors in the economy. Infrastructure has a cross-sectoral character, providing the conditions for the effective formation of other industries or activities, and performs the function of integration between states, regions and industries. Therefore, infrastructure does not directly create material wealth, but performs a supply function. In this regard, an important role in the development of infrastructure belongs to the state, local authorities.

It should be noted that the tourism enterprise should form the main directions of its development and choose the appropriate economic strategy based on certain criteria, and strive to achieve appropriate indicators that characterize the implementation of these criteria.

The President of the Republic of Uzbekistan Shavkat Mirziyoyev said: "We will continue consistent reforms in the development of tourism in 2021. Special attention will be paid to the development of pilgrimage tourism and domestic tourism. In addition, 1 trillion soums will be allocated from the budget to improve land, water and road infrastructure around tourist facilities" in his Address to the Oliy Majlis, [13]. This is a study of special importance in determining the criteria and indicators for improving the effectiveness of the development of regional tourism infrastructure in the country.

\section{LITERATURE REVIEW}

Scientific basis of problems related to the development of the tourism market, tourism industry and its infrastructure, functions, subjects of tourism infrastructure, mechanisms of tourism market regulation, tourist recreation, restaurants and hotels, tourism policy Zorin I.V., Kvartalnov V.A. [11], Pardaev M.Q. [10], Birjakov M.B. [4], Beklaryan L.A., Pshennikov A.S. [5], Morozov M.A. [5], Tuxliev I.S., Hayitboev R., Safarov B.Sh., Tursunova G.R. [12].

Socio-economic significance of the tourism market, its components, main tasks and functions, tourist facilities, tour operators and travel agents, regulation of the tourism market, goals and objectives of state policy in tourism, methods of assessing the effectiveness of tourism services, tourism infrastructure, tourism industry state support measures Zhukova M.A. [6], Alimova M.T. [1], Ernazarov O.E. [2], Mamatqulov X.M. [7], Arxipova V.F., Devizov A.S. [3].

Also, the essence and content of tourism infrastructure, the activities of various levels of tourism infrastructure in the field of economy and management, the role of the state in the development of tourism infrastructure, organizational elements of regional tourism infrastructure, indicators of tourism development and levels of infrastructure development Mamatkulov H.M. [7], Morozov M.A. [8], Norchaev A.N [9].

\section{RESEARCH METHODOLOGY}

The study used a dialectical and systematic approach, comparative and comparative analysis, statistical approaches and grouping methods to assess the effectiveness of infrastructure components.

\section{ANALYSIS AND RESULTS}

One of the main indicators of tourism development is the achievement of economic efficiency. From this point of view, the increase in both absolute and relative indicators of economic efficiency of employment 
is directly related to the level of development of tourism infrastructure. The study of the main factors and conditions for the development of tourism infrastructure and increase its efficiency in the process of modernization of the economy will allow to determine its main criteria.

Criteria that allow the evaluation of specific events and processes can be one or more. Criteria also serve to determine the scale of events and processes, its level. To determine this essence and the main tasks, it is necessary to take into account the end results of the efficiency of tourism enterprises. The final results are reflected in certain indicators. At the same time, it is expedient to determine the criteria and indicators of development of tourism enterprises.

Taking into account the specific features of the market of tourism services, the organizational, social, economic and other aspects of the activities of tourism enterprises and the development of its infrastructure are reflected in the following criteria. In our country, modern tourism is developing as a leading sector of the economy. Accordingly, all social, economic and other aspects of the economic efficiency of economic entities operating in this sector are reflected in the following criteria:

- achieving high efficiency of tourism products and services;

- reduction of the relative level of expenditures on tourism products and services; - increasing labor productivity in tourism enterprises by maximizing customer satisfaction;

- increasing profitability in tourism enterprises (Figure 1).

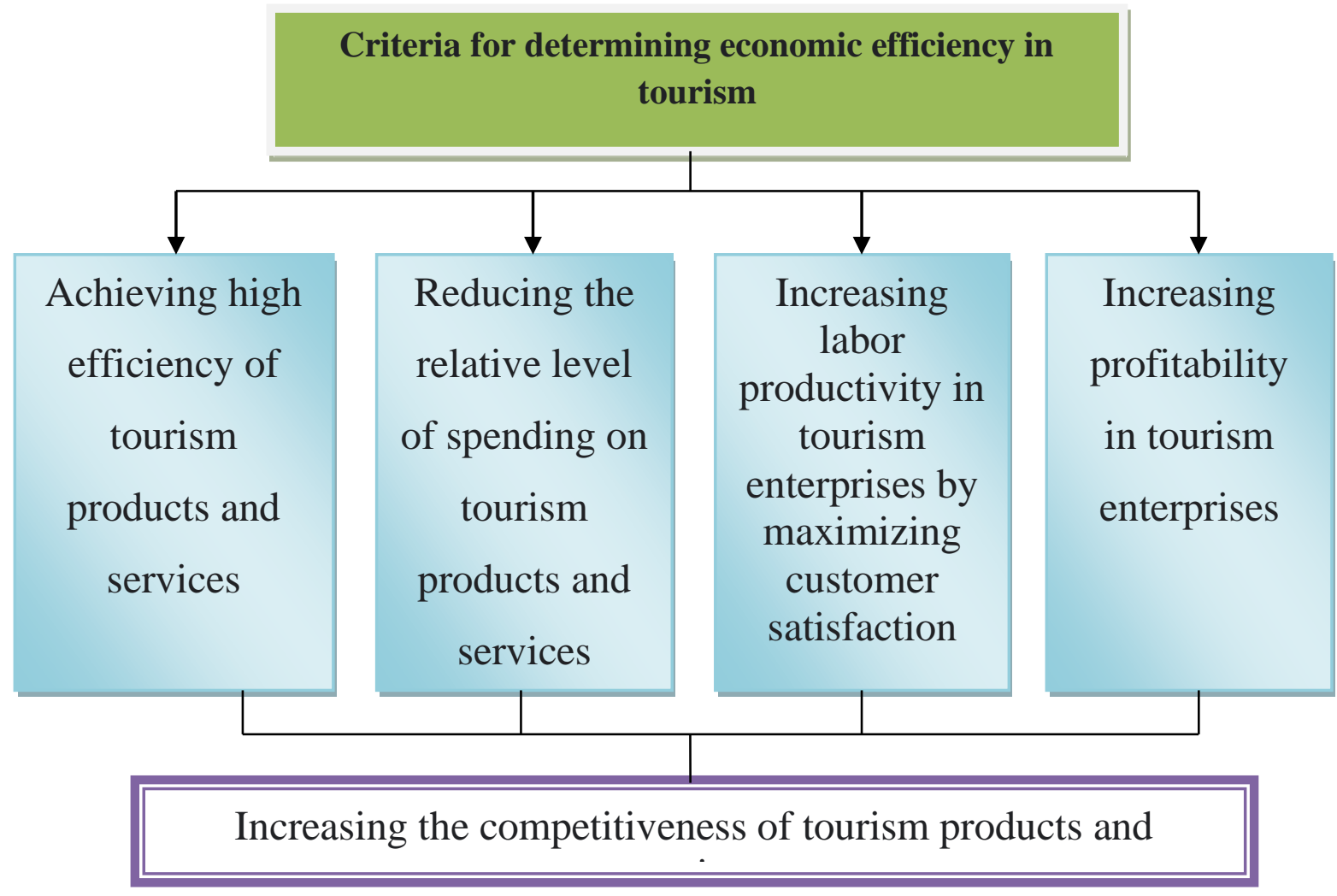

Figure 1. Criteria for determining economic efficiency in tourism

These criteria are determined on the basis of indicators that reflect the efficiency of economic activity in the tourism industry. The economic literature provides different methods of assessing socioeconomic performance indicators, for example, classifications by scale, level of resource use, importance of indicators, their role in decision-making, degree of generalization [6, p. 14].

In general, the economic efficiency of a tourism enterprise is determined by the ratio of the result required to the cost to ensure efficiency.

$$
I_{s}=\frac{N}{X}
$$

where: $I_{S}$ - an indicator of economic efficiency; $N$ - result obtained, effective; $X$ - the cost required to achieve this result. 
There are many different efficiency indicators that characterize different aspects of the activities of tourism enterprises in the economy. In this regard, they are classified at the national (at the level of the national economy), regional (at the level of certain regions) and micro levels (at the level of the enterprise or its department).

Economic calculations use absolute, incremental, and comparative performance indicators. Absolute indicators are determined by the ratio of absolute efficiency to total costs, while relative indicators are determined by the ratio of the difference in efficiency to the difference in costs.

If the company needs to build a new facility or introduce new equipment, then it is necessary to choose the most efficient option. For the initial calculations, the coefficient of specific economic efficiency is used:

$$
K_{c i c}=\frac{C_{2}-C_{1}}{K_{1}-K_{2}}
$$

where: $K_{c i c}$ - the coefficient of specific economic efficiency; $C_{1}, C_{2}$ - current costs on options, $C_{2}>C_{1}$ ; $K_{1}, K_{2}$ - capital expenditures on options, $K_{1}>K_{2}$.

The obtained coefficient of comparative economic efficiency is compared with the normative coefficient of comparative economic efficiency of capital investments $\left(K_{n}\right)$. If $K_{c i c}>K_{n}$, then this option is selected, which requires a large amount of capital expenditure (but in this case requires a small amount of current expenditure).

After comparing several options, the following cost minimization formula is used:

$$
X_{v}=X_{j}+K_{n} \times K_{i} \rightarrow \min
$$

where: $X_{v}$ - costs incurred under this option; $K_{i}$ - capital expenditures on options; $X_{j}$ - current costs on options; $K_{n}$ - normative coefficient of specific economic efficiency of capital investments.

A number of options are chosen to minimize costs. We will look at how this technique can be used in calculations. Assume that the hotel management wants to master the new technological equipment. There are three different types of techniques that require different capital and current costs. Table 1 shows the cost value for each option based on the following condition, i.e., when Kn $=0.16$. The calculation is based on formula 3. As can be seen from the table, the first is the best option for the hotel to master the new equipment.

To determine the effective formation of tourism enterprises, it is necessary to directly assess the effectiveness of the use of available resources. To do this, a comparative indicator of resource efficiency is used.

Table 1 Calculation of costs incurred

\begin{tabular}{|l|l|l|l|}
\hline Variant numbers & $\begin{array}{l}\text { Capital expenditures } \\
(\mathbf{m l n} . \mathbf{s u m})\left(\boldsymbol{K}_{\boldsymbol{i}}\right)\end{array}$ & $\begin{array}{l}\text { Current expenses } \\
(\mathbf{m l n} . \mathbf{s u m}) \mathbf{( \mathbf { X } _ { \mathbf { j } } )}\end{array}$ & $\begin{array}{l}\text { Costs incurred (mln. } \\
\text { sum) }\left(\mathbf{X}_{\mathbf{v}}\right)\end{array}$ \\
\hline 1 & 30 & 2 & $2+0,16 \times 30=6,8$ \\
\hline 2 & 20 & 4 & $4+0,16 \times 20=7,2$ \\
\hline 3 & 25 & 3 & $3+0,16 \times 25=7,0$ \\
\hline
\end{tabular}

Any enterprise (especially a tourism enterprise) uses extensive and intensive ways of using resources in its development. In the extensive approach, the increase in the volume of production of goods (services) is due to the attraction of additional resources, that is, the increase in efficiency is achieved through an increase in the use of resources. In the intensive approach, the increase in the volume of production of goods (services) is due to the use of new, high-performance equipment and new technologies (in which the use of resources may even decrease), ie the quality of resource use increases [8].

In order to increase resources, the company must determine the efficiency of the use of additional units of resources, ie the growth rate of economic efficiency:

$$
\varepsilon=\frac{F_{2}-F_{1}}{R_{2}-R_{1}}
$$

where: $\varepsilon$ - growth rate of economic efficiency; $F_{2}, F_{1}$ - initial volume of resource use and the effective value in its increase; $R_{2}, R_{1}$ - initial and incremental volumes of resources.

The economic significance of this indicator is that it represents the efficiency of the use of additional resources, as opposed to the indicator $\left(S_{m}\right)$, which characterizes the efficiency of the use of total resources (absolute efficiency). 
On the basis of a graph known as linear incremental efficiency, it is possible to construct a mathematical relationship of each resource effect to the final result value. In simplified form, this function represents the use of the general economic law of decreasing efficiency for each additional unit of resource.

It may be the case that this resource does not affect the end result, i.e. the efficiency of its use is zero. Figure 2 shows the graphical function of resource use efficiency.

A surplus of resources is such a resource that the efficiency utilization is zero for a complex production situation.

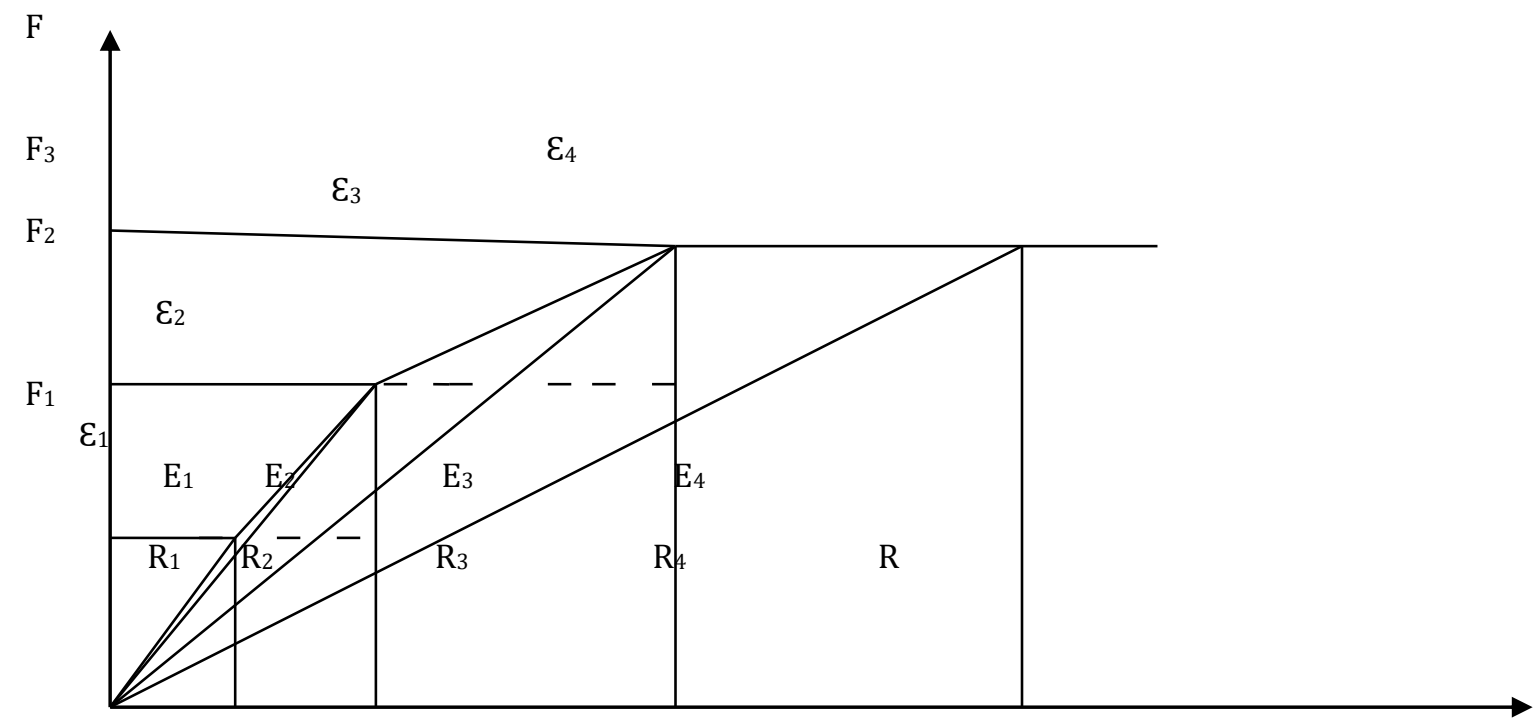

Figure 2. Resource utilization efficiency function

Therefore, it can be concluded from this:

- In the case of extensive growth, the efficiency of the formation of tourism enterprises may not increase (overall efficiency may increase);

- In extensive growth there is always a time when the efficiency of using an additional unit of resource is zero, i.e. resources cannot be systematically increased without applying any additional changes to increase the end result. Usually this is related to the production capacity of the enterprise. The profitability of innovation is related to the integral efficiency [2].

Figure 2 clearly shows two indicators of economic efficiency ( $E$ and $\varepsilon$ ) representing the absolute and relative growth of resource use. In general, the algorithm for calculating them is based on the following formula:

$$
E_{i}=\frac{F_{i}}{R_{i}} \quad \varepsilon=\frac{F_{i+1}-F_{i}}{R_{i+1}-R_{i}}=\frac{\Delta F_{i}}{\Delta R_{i}},
$$

Absolute efficiency coefficients are defined as the ratio of the absolute volume of the result to the volume of costs and represent the average value of the result per unit of cost. They are less sensitive to resource stagnation.

As can be seen from Figure 2, at point R4, at the value of the resource, it is not used at all (S4 $=0$ ), while the absolute efficiency index has a positive value that is large enough (E4>0). Considering the description of the efficiency line, it can be concluded that the absolute indicators are not suitable for the forecast calculations of the evaluation of the efficiency of additional resource mobilization.

The efficiency growth coefficient is defined as the ratio of results growth to cost growth and reflects the change in results in an additional unit of resources involved. They can be used for forecast calculations per additional unit of resources involved. For their calculation it is necessary to create an economic-mathematical model of the research object, on the basis of which the calculation of these indicators is carried out. In economic-mathematical modeling, they correspond to a two-sided assessment of resources.

A two-way evaluation is an evaluation of the efficiency of using an additional unit of resource, indicating how much the resulting value changes when a unit resource value changes in an infinitely small fraction (extensive growth). 
In the real economy, both absolute and relative indicators are used to assess the economic efficiency of enterprises.

For hotel business enterprises, there are special indicators for assessing the cost-effectiveness associated with typically occupying a room fund. Such indicators include the coefficient of occupancy of hotels, calculated by the following formula:

$$
K_{b}=\frac{Q_{k-d}}{Q_{k-m} \times T},
$$

where: $\mathrm{Kb}$ - occupancy rate of the hotel, which can be calculated both as a percentage and in relative units $\left(0<\mathrm{K}_{\mathrm{b}}<1\right)$; $\mathrm{Q}_{\mathrm{k}-\mathrm{d}}$ - the total number of sold numbers (beds-days); $\mathrm{Q}_{\mathrm{k}-\mathrm{m}}$ - number of rooms offered for sale (bed space); $\mathrm{T}$-number of days (years) in the reporting period for which this indicator is calculated.

This figure is the most important for any hotel, so every hotel will try to increase it. This is especially true of our national hotels. Because usually they cheat from placing their main income. As long as fixed costs are always high in hotel farms. The closer this figure is to the unit (the hotel is fully occupied), the higher the profit. In practice, due to various reasons (technical, sanitary, etc.), not all rooms are ready for use during a certain period. Therefore, there are indicators of the maximum possible and actual number of rooms (bed-days) for the calculation of the fund of rooms with common hotels. The maximum possible number fund (capacity) is the product of the total number of numbers (beds) in the number of days in the year in which they can be used.

$$
F_{\text {max }}=Q_{g} \times T_{g}+\sum_{m} Q_{m} \times T_{m}
$$

where: $F_{\max }$ - maximum possible number fund; $Q_{g}, Q_{m}$ - number of numbers used annually and seasonally (bed-place); $T_{g}, T_{m}$ - number of days in the year, the number of days in the season.

Actual number funds are the number of actual numbers (bed-places) that can be used over a given period of time multiplied by the number of days used.

The hotel occupancy rate can be calculated using the break-even point calculation formula.

$$
K_{b}=\frac{Z_{d}^{b}}{N_{b}-Z_{u}^{b}}
$$

where: $Z_{d}^{b}$ - average fixed costs per room (bed space); $Z_{u}^{b}$ - variable costs per room; $N_{b}$ - room price (bed-place) (different prices are used for the average price of the room).

Using this formula in the calculation of the occupancy rate, it is possible to calculate the minimum cost of rooms that will cover all the costs of the hotel.

To assess the efficiency of the hotel Swiss service for the sale of rooms, you can use the indicator of the average cost of selling a hotel room at their different prices:

$$
N_{\text {aver }}=\frac{V_{t}}{Q_{c n}},
$$

where: $N_{\text {aver }}$ - average selling price of the hotel room (average daily price); $V_{t}$ - revenue from the sale of numbers (income); $Q_{c n}$ - total number of numbers sold.

The higher the occupancy rate of a hotel, the higher the average price of selling a hotel room can be, i.e. the average price of selling a room depends on the level of occupancy of the hotel. The most popular way to optimize the average daily price of a hotel room is to cover the deficit and manage interest income.

The first method is that unoccupied numbers, for some reason, still attract demonstrative attention in moments of attention. For example, it is wider, it is conveniently located, it has the best view of the window, and so on.

The second method is that customers reserve the numbers and pay for it long before they arrive, so they can pay it in advance at preferential rates. At the same time, in order to increase the income from the use of the room fund, it is necessary to forecast the demand for the interests of customers in advance and determine the optimal prices for the room in accordance with this forecast. In calculating the number price according to this methodology, it is necessary to take into account not only the time to reserve, but also the type to be reserved. For example, if a person receives a double room or a deluxe room, then such 
a number should not be less than the price of a standard single room. If the room is occupied by two or more people, then it is necessary to bring more income to the hotel than if one person occupies the room.

For guests, the indicator of security, which shows the average number of tourists per room sold, is also important:

$$
C_{\text {aver }}=\frac{N_{k}}{Q_{c n}}
$$

where: $C_{\text {aver }}$ - the average number of visitors to a single sold number; $N_{k}$ - the total number of guests staying at the hotel during the reporting period.

Profit as an economic category represents the net income generated in the field of material production in the course of entrepreneurial activity. In the context of commodity-money relations, net income at the level of tourism enterprises takes the form of profit. The initial formation of profit is the income from the sale of products (works, services). The tourism industry earns money from this by setting prices for products and services and sells them to consumers. To determine the financial results of the tourist enterprise for a certain period, it is necessary to compare the revenue from the sale of the product (work, service) with the cost of its production (service). In a market economy, the formation of a tourism enterprise, regardless of the form of ownership and type of activity, is determined by the possibility of obtaining sufficient profits or income.

Profit analysis in enterprises of the tourism industry includes the following main tasks:

- study the structure of profits for the reporting period and the previous year;

- identification of factors influencing changes in the dynamics of profits in the increase or decrease in profits;

- analysis and study of the composition of non-production profits and losses;

- identify and evaluate potential reserves for profit growth.

Endogenous (internal) and exogenous (external) factors affect the volume of profits in a tourism enterprise and its dynamics. In practice, the external factors influencing the activities of the enterprise are market conditions, the level of prices for the consumption of raw materials and fuel and energy resources, the rate of depreciation. Factors such as the price of the product sold and the level of wages depend to some extent on the activities of the enterprise. Factors related to the activities of the enterprise include the level of economic activity, the competence of management and managers, the competitiveness of products and services, the organization of labor and production, the level of labor productivity, the state and efficiency of production and financial planning.

These factors do not always have a direct impact on profits and, above all, on the volume and cost of products sold. The pursuit of profit directs the tourism industry to increase the volume of products and services produced for the necessary consumers, reducing the cost of their production. In an increasingly competitive environment, this is achieved not only through entrepreneurial goals, but also through the satisfaction of social needs.

The structural analysis of the profit of the tourism enterprise shows that the main source of its formation is the profit from the sale of products (works, services). It reflects the final results of the enterprise not only in production, but also in transactions. The official calculation of the profit from the sale of the product can be expressed as follows:

$$
F=T_{r}-N_{t}-X_{t}-B_{x}
$$

where: $F$ - profit from product sales; $T_{r}$ - net revenue from product sales; $N_{t}$ - cost of the product; $X_{t}$ - commercial expenses; $B_{X}$ - management costs.

An important condition for the profit from the sale of tourism products and services are an increase in sales, a decrease in cost, an increase in product quality and competitiveness, modern payments to buyers of products and services.

In addition to the analysis of profits from the sale of products (works, services) as the main source of profit for the reporting period, it is necessary to conduct a comprehensive analysis of nonproduction profits and losses. The financial results of non-manufacturing operations are also an integral part of the profit. In a market economy, their influence on the formation of the final financial results of the enterprise is growing significantly.

The use of profits in enterprises of the tourism industry represents the process of formation of enterprise reserves and funds for the financing of production needs and the development of the social sphere. 


\section{CONCLUSION/RECOMMENDATIONS}

An important factor in achieving economic efficiency for tourism enterprises is to reserve them for future use. This includes provisions for doubtful debts and provisions to prevent the impairment of securities, which are included in non-production costs in the taxation of profits. Reserves are formed on the basis of deductions from net profit and, as a rule, include a fund of funds created and used under separate legal, regulatory and constituent documents.

The purpose of creating reserves for tourism enterprises is different, that is, to ensure the uninterrupted financing of large expenditures; reserves to cover doubtful debts may include. Doubtful debts are receivables of an enterprise that have not been repaid on time under a clear agreement and have not been secured by appropriate guarantees. Provisions for doubtful debts can be created only on accounts receivable, which are formed due to non-performance of obligations under the contract of sale of goods and services. The amount of the established reserve is determined separately for each of the doubtful debts depending on the solvency of the debtor and their prospects for full or partial repayment of the debt.

In the creation and formation of reserves, the tourism enterprise must meet the following basic requirements:

- strict consideration of the targeted use of resources;

- it is necessary to follow the existing legislation and constituent documents in the creation of reserves;

- the order of formation and use of reserves should be noted in the adoption of accounting policies in the enterprise;

- should be based on the volume of reserves created;

- at the end of the year, the amount of unused reserves lies in the mandatory inventory, after which their list is compiled.

An important indicator that represents the final financial result of a tourism enterprise is profitability. An increase in the profitability of a tourism enterprise leads to an increase in net profit as an important indicator of economic efficiency.

The above criteria and indicators can be used to assess the effectiveness of the development of components of tourism infrastructure, regulatory mechanisms and the methodological framework for the development and implementation of targeted comprehensive programs for the development of the industry.

\section{REFERENCES}

[1]. Alimova M.T. Development features and trends of the regional tourism market (on the example of Samarkand region) // I.f.d. diss. - Samarkand: SamISI, 2017. 25-26-p.;

[2]. Ernazarov O.E. Methods of Evaluating the Efficiency of Innovations in Industrial Enterprises. International Journal of Research - 2020. - Volume 07 - Issue 07;

[3]. Arkhipova V.F., Devizov A.S. On infrastructure as a determining factor in the development of tourism in the region. URL: http: //www.roman.by/r-78201.html;

[4]. Birzhakov M.B. Introduction to tourism. - SPb .: Gerda Publishing House, 2004;

[5]. Beklaryan L.A., Pshennikov A.S. On some aspects of the methodology for studying regional problems // Journal of Audit and Financial Analysis. -№4. 2001;

[6]. Zhukova M.A. Management in the tourism business: a textbook. - 2nd ed., Erased. - M .: Competition, 2006 --- 193 p., 14 - p.;

[7]. Mamatkulov X.M. Tourism infrastructure. Study guide. - T .: Publishing House of the National Society of Philosophers of Uzbekistan, 2011. Pages 4-5;

[8]. M.A. Morozov Infrastructure support of entrepreneurial activity in tourism: monograph. - M .: RosNOU, 2005;

[9]. Norchaev A.N. Expected changes and opportunities in tourism infrastructure. Scientific electronic journal "Economy and Innovative Technologies". № 1, January-February, 2019;

[10]. Pardaev M.Q. and others. Development of services, services and tourism: problems and their solutions. Study guide. - T .: «Economy and Finance», 2008. - P. 133.;

[11]. Tourist terminological dictionary: reference and methodological manual / Avt.-comp. I. V. Zorin, V. A. Kvartalnov. - M .: Soviet sport, 1999;

[12]. Tuxliev I.S., Hayitboev R., Safarov B.Sh., Tursunova G.R. Basics of tourism. Textbook. Ministry of Higher and Secondary Special Education of the Republic of Uzbekistan. - T .: «Science and technology», 2014. 151-p.; 
[13]. Address of the President of the Republic of Uzbekistan Shavkat Mirziyoyev to the Oliy Majlis, 30.12.2020. https://review.uz/oz/post/poslanie-prezidenta-uzbekistana-shavkata-mirziyoyeva-oliymajlisu;

[14]. UNWTOTourism Highlights.Edition 2017. - Madrid, WTO Publications Department. - 2018;

[15]. Travel \& Tourism Economic Impact 2016 World [Electronic source]:http://www.wttc.org. 